\title{
Measuring Educational Sustainability
}

\author{
Rani G. Selvanathan ${ }^{1}$ \\ ${ }^{1}$ Management Department, West Chester University, West Chester, PA, 19383, USA \\ Correspondence: Rani G. Selvanathan, Management Department, West Chester University, West Chester, PA, 19383, \\ USA. E-mail: Rselvanathan@wcupa.edu
}

Received: December 3, 2012

Accepted: December 18, 2012

Online Published: January 7, 2013

doi:10.5430/ijhe.v2n1p35

URL: http://dx.doi.org/10.5430/ijhe.v2n1p35

\begin{abstract}
There are many definitions that are attributable to the meaning of sustainability. Sustainability can be viewed as long-lasting, effective result of a project, venture, action, or investment without consuming additional future resources. Because of the wide nature of its applicability, a universal measure of sustainability is hard to come by. This paper proposes that in addition to the often explored four types of economic, financial, social, and environmental sustainability the need exists for a fifth aspect of sustainability viz. educational. The fifth aspect proposed in this paper is extremely important to educational institutions which form the future workforce. The paper proposes a universal model to measure educational sustainability and continues with simulating sustainability as a function of several factors.
\end{abstract}

Keywords: Educational sustainability, Measurement, Model, Improving retention

\section{Historical Background and the Trend of Modern Learning}

Learning is a continuous process in which knowledge is imparted or shared among the participants of the learning process. Two broad classes of participants are involved in this process; the teacher and the student. The objectives of learning process is for the student to get exposed to new ideas and concepts, understand the need for the concepts, and become capable of applying the knowledge acquired to practical situations.

Learning can take place anywhere from home, school, and/or work environments. Researchers and educators have pondered over the most effective way in which this transfer of knowledge can take place. It is to be noted that over time, the mode of exchange of knowledge has shifted and moved from a teacher centered to a student centered approach.

The importance of learning and the crucial role it plays in the ongoing development of economy resulted in a formal classification of what learning should accomplish. A committee of educators chaired by Benjamin Bloom proposed one such classification known as Bloom's Taxonomy (1956) which was later revised in 2000.

The new objectives of Bloom's Taxonomy are now defined by Anderson and Krathwohl (2001) as: Remembering Retrieving, Recognizing, and Recalling relevant knowledge from long-term memory and are comprised of:

- Understanding: Constructing meaning from oral, written, and graphic messages through interpreting, exemplifying, classifying, summarizing, inferring, comparing, and explaining.

- Applying: Carrying out or using a procedure through executing, or implementing.

- Analyzing: Breaking material into constituent parts, determining how the parts relate to one another and to an overall structure or purpose through differentiating, organizing, and attributing.

- Evaluating: Making judgments based on criteria and standards through checking and critiquing.

- Creating: Putting elements together to form a coherent or functional whole; reorganizing elements into a new pattern or structure through generating, planning, or producing.

Objectives to be achieved in a course can only be achieved progressively from remembering to creating as illustrated in Figure 1. 


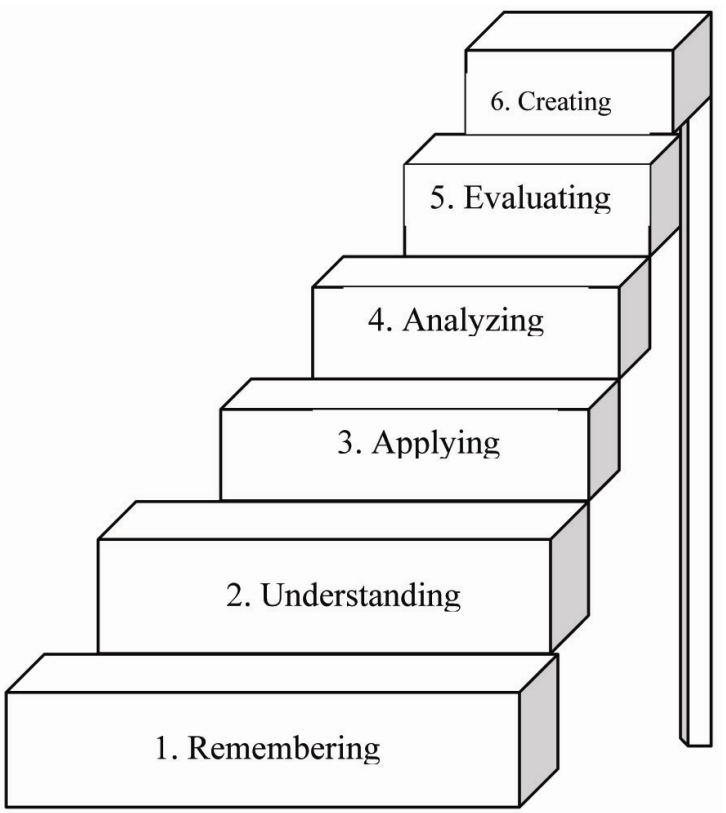

Figure 1. Stages to Reach the Ultimate Goal of Instruction

Effort is made by educators all over the world to ascertain that their respective courses are constructed so as to meet the objectives prescribed. Under "perfect" scenario, incorporating the above objectives in any course will make the course a highly effective or highly sustainable one.

\section{Sustainability}

Education is the process of acquiring knowledge and skills not possessed currently by those seeking it. The acquisition can come from various sources such as exposure to real-life situations at work or elsewhere or at formal institutions such as colleges and universities which possess faculty who are highly cognizant with the knowledge and technology being sought. The knowledge acquisition can take place in physical locations or on-line with the help of the state of art technology. The objective of the educational institution is to make sure that the knowledge transferred is sustainable. This necessitates that in addition to having

Economic sustainability

Social sustainability

Environmental sustainability

Cultural sustainability,

an educational institution should also make sure of the assurance of the fifth dimension of sustainability i.e.

Educational sustainability

Sustainability can be defined as the propensity of an object or a program to continue and to grow in time. It has been in use in a wide variety of situations like agricultural technologies to improve crop and livestock production, implementation of social programs to name a few.

Sustainability is a concept that should originate from the organization itself with suggestions and guidance from entities external to the organization. It reflects the property of a program to benefit from the currently available resources and continue to grow in time. The most quoted and apt description of sustainable development is from a report by The World Commission on Environment and Development. The report contains an overall definition of sustainability which is known as the "Brundtland Definition" (1987) and states that a sustainable development is the one "meets the needs of the present without compromising the ability of future generations to meet their own needs"

Extensive work continues to be done in the fields of:

Environmental sustainability

Achieved when rates of depletion of natural resources is not greater than rates at which they are renewed.

Human sustainability

Per Report of the World Commission on Environment and Development (1987), one common future sustainability goal is to meet the needs of the present without compromising the ability of future generations to meet their own needs. 
Economic sustainability

It measures the ability to support a defined level of economic production indefinitely in addition to having low and stable inflation rate and low unemployment rate. Focus should be shifted from "growth" to "growth combined with conservation of available resources".

Social sustainability

Elements of the community that contribute to social well-being of formal human services such as: health, education, social services, recreation and culture, design of communities to promote social sustainability become necessary. Social sustainability is the practice of creating a diverse and equitable society that successfully meets the basic social needs of citizens. Aspects like supply, social resources, equal opportunity, and diversity are taken into consideration in order to assess this measure.

Assessing the sustainability of a program is not a difficult task in each of the above categories because of the relative ease of defining measurable outputs.

An educational institution should also make sure of the assurance of the fifth dimension of sustainability i.e. educational sustainability.

\section{Educational Sustainability}

Given the nature of sustainability, the challenges faced by educational institutions, as with all the others, are measurement, maintenance, and growth. It is to be recognized that maintaining sustainability in one field could upset the sustainability balance of the remaining four. In this paper, we consider education as the additional fifth factor that influences the way how the other four perform. Education should therefore be treated as one of the important pillars of a "sustainable" economy. Weakness or lack luster performance of any of the five factors is likely to negatively affect the sustainability as a whole. It is seen that right education will enable the building and maintaining of the other four factors. The dependence of sustainability on the strength of the five factors is depicted in Figure 2. We will now examine educational sustainability, find out what it depends on and suggest a way to measure it.

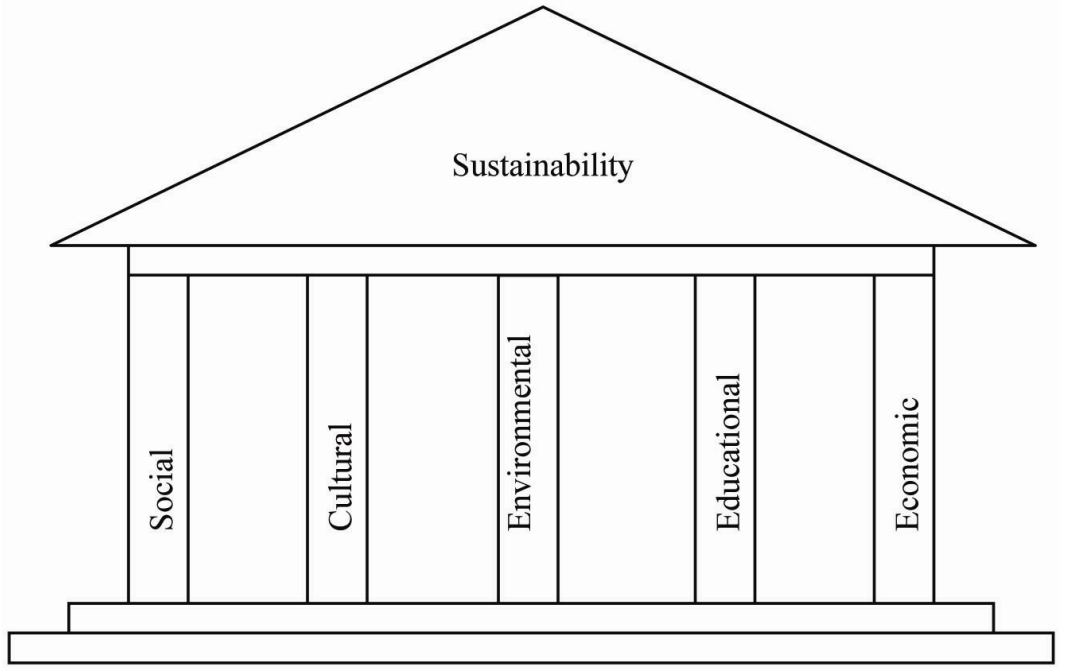

Figure 2. Factors Supporting Sustainability

A brief tour of current pedagogical practices in existence today seems relevant here. The pedagogical methods to facilitate the transfer of knowledge from an instructor to a student range over a wide spectrum as indicated below:

\subsection{Lectures}

This marks the traditional way of transfer of knowledge from teacher to student. While providing a medium for the transfer of maximum amount relevant knowledge, this mode, when used alone, could limit the effectiveness of the knowledge imparted.

\subsection{Lectures interspersed with creative activities}

Puzzles and games have been used to involve student participation. Saunders and Christopher (2003) stress the need for alternative teaching methods to improve student attention. The positive effect of puzzles on learning is evident, irrespective of the age of the students. A brief review of various puzzles that are in use at the current time follows:

- Wooden Puzzles: Good for children between the ages of 1 and 8 it improves motor skills and hand-eye coordination.

- Jigsaw Puzzles: The level of difficulty can be varied according to the age of the student and elucidates spatial concepts and problem-solving. 
- Word Search Puzzle: It is made up a block of letters containing words spelt horizontally, vertically or diagonally and improves spelling and one's ability to identify relevant information from a plethora of information. This skill is also known as figure-ground perception.

- Hidden Picture Puzzle: This has similar effect as a word search puzzle.

- Crossword Puzzle: This can be built for students ranging from 7 years and above and strengths vocabulary, memory skills, reasoning skills, and spelling skills.

- Logic Puzzles: These can be either word or mechanical and promote logical thinking and deductive and inductive reasoning.

- Patterns Puzzle: Coming in any combination of shapes, colors, numbers, or letters, they aid in logical progressions as well as deductive and inductive reasoning.

- Mazes: These necessitate the finding of the right path to reach a goal and promote logical progression and deductive reasoning.

- Riddles and Brain teasers: They are short descriptions of events which encourage students to think "outside the box".

\subsection{Collaborative Learning}

These are implemented in several different ways: working on short essay questions and mini cases based on the material currently being covered in classroom; end of the semester projects and presentations; requiring students to maintain a journal addressing the issues currently being discussed; simulation; and a full blown case analysis. Students backed by their individual backgrounds learn to benefit from each other through group interaction Gerlach (1994). Lectures by instructors and invited guest speakers will continue to be offered as supportive material, Smith and McGregor (1992).

Whether done individually or in groups, the positive effects of collaborative learning depends to a large extent on the size of the class, the level of preparation of the student prior to taking a class and their own interest in the material being discussed. Also when done in groups, one may risk the non-performance of some students due to social loafing and the tendency to use division of labor could make a student work on a portion of the case, thus making the knowledge acquired, incomplete

Knowledge acquisition in on site/on line class rooms has gradually undergone changes over time. A one hundred percent teacher centered (lecture) approach is proving to be ineffective and it has been found that knowledge acquisition and retention is better achieved through participation of students. At the other end of the spectrum is a completely student centered approach with the instructor playing the role of liaison and disseminator of information. Table 1. summarizes the various teaching methods that are in current use and identifies their ability to develop skills, as indicated in columns 1 through 6, per the revised version of Bloom's taxonomy (2001). Each teaching method addresses some or all of the skills and is accorded a rank depending on the number of skills it addresses. The methods that are applicable in a higher educational situation are marked with an asterisk.

Table 1. A Rating of Various Teaching Methods (Delivery)

\begin{tabular}{|c|c|c|c|c|c|c|c|}
\hline $\begin{array}{l}\text { Objectives of a course } \\
\text { per Bloom's Taxonomy }\end{array}$ & $\begin{array}{l}\text { Remember } \\
1\end{array}$ & $\begin{array}{l}\text { Understand } \\
2\end{array}$ & $\begin{array}{l}\text { Apply } \\
3\end{array}$ & $\begin{array}{l}\text { Analyze } \\
4\end{array}$ & $\begin{array}{l}\text { Evaluate } \\
5\end{array}$ & $\begin{array}{l}\text { Create } \\
6\end{array}$ & Rank \\
\hline Lecture only * & $\mathrm{X}$ & $\mathrm{X}$ & & & & & $2 / 6$ \\
\hline \multicolumn{8}{|l|}{ Lecture + Activities: } \\
\hline Wooden Puzzles & $\mathrm{X}$ & $\mathrm{X}$ & $\mathrm{X}$ & & & $\mathrm{X}$ & $4 / 6$ \\
\hline Jigsaw Puzzle & $\mathrm{X}$ & $\mathrm{X}$ & $\mathrm{X}$ & $\mathrm{X}$ & & & $4 / 6$ \\
\hline Word Search Puzzle & $\mathrm{X}$ & $\mathrm{X}$ & $\mathrm{X}$ & & & & $3 / 6$ \\
\hline Hidden Picture Puzzle & $\mathrm{X}$ & $\mathrm{X}$ & & & & $\mathrm{X}$ & $3 / 6$ \\
\hline Crossword Puzzle * & $\mathrm{X}$ & $\mathrm{X}$ & $\mathrm{X}$ & $\mathrm{X}$ & $\mathrm{X}$ & & $5 / 6$ \\
\hline Logic Puzzle & $\mathrm{X}$ & $\mathrm{X}$ & $\mathrm{X}$ & $\mathrm{X}$ & $\mathrm{X}$ & & $5 / 6$ \\
\hline Pattern Puzzle & $\mathrm{X}$ & $\mathrm{X}$ & $\mathrm{X}$ & $\mathrm{X}$ & & & $4 / 6$ \\
\hline Maze & $\mathrm{X}$ & $\mathrm{X}$ & $\mathrm{X}$ & $\mathrm{X}$ & $\mathrm{X}$ & $\mathrm{X}$ & $5 / 6$ \\
\hline Riddles and Brain Teasers & $\mathrm{X}$ & $\mathrm{X}$ & $\mathrm{X}$ & $\mathrm{X}$ & $\mathrm{X}$ & & $5 / 6$ \\
\hline \multicolumn{8}{|l|}{ Collaborative Learning: } \\
\hline $\begin{array}{l}\text { Short, Essay Questions, * } \\
\text { and mini cases }\end{array}$ & $X$ & $X$ & & & & & $2 / 6$ \\
\hline Semester End Projects * & $X$ & $\mathrm{X}$ & $\mathrm{X}$ & $\mathrm{X}$ & $\mathrm{X}$ & & $5 / 6$ \\
\hline Journal on Current Issues * & $\mathrm{X}$ & $\mathrm{X}$ & & $\mathrm{X}$ & & $\mathrm{X}$ & $4 / 6$ \\
\hline Case Analysis * & $\mathrm{X}$ & $X$ & $\mathrm{X}$ & $X$ & $\mathrm{X}$ & $X$ & $6 / 6$ \\
\hline
\end{tabular}


It may appear from the table that case analysis is the best mode of delivery with a ranking of $6 / 6$. The model proposed in this paper elaborates the fact that the success of case analysis in maintaining and improving the sustainability of a course is contingent on the three other factors viz. skills (S), effort (E), level at which the course is taught (L) A rating low on these factors will certainly reduce the sustainability of using the said method.

\section{Improving Educational Sustainability}

It is well known fact that a factor that is measurable is controllable and could be improved upon. In this paper, we present a way in which such a measurement can be done. Sustainability of a course can be defined as the extent to which a student is able to retain the concepts presented in a classroom. This long-term retention can be used, at a later date, to apply the concepts to a practical situation. A course that is sustainable, in its true sense, will meet all the requirements of Bloom's taxonomy. The sustainability pyramid as shown in Figure 3 illustrates the relative importance of the parameters affecting sustainability starting from the most basic one of "Skills".

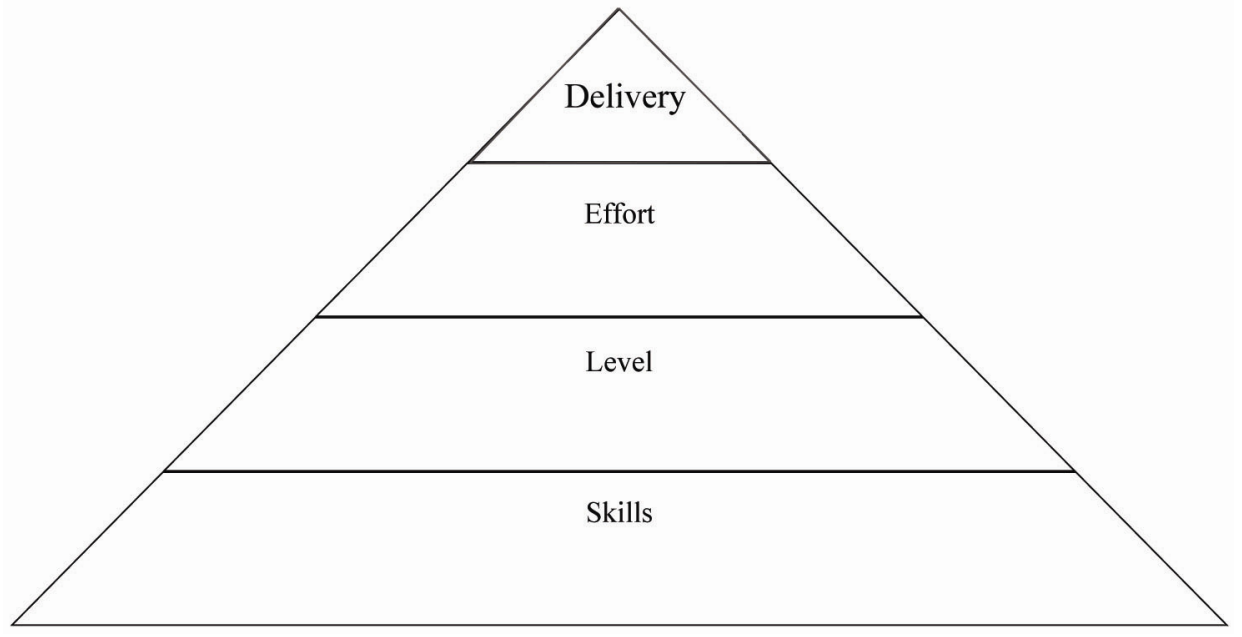

Figure 3. Sustainability Pyramid

A course material that is retained and later on applied by a student is considered sustainable. The sustainability of a course can be defined as a function of four parameters: Skills, Level at which a course is taught, Effort, and Delivery mode. The presence of each of the four parameters, in varying degrees is essential in determining the effectiveness of a "classroom". Here, the word "classroom" is used to represent a media, real or virtual, where knowledge and understanding is imparted or learnt.

Educational sustainability can be linked to these parameters in two ways: additive or multiplicative. Let

$S$ represent the parameter for Skills

$\mathrm{L}$ for Level at which a course is taught

E for Effort

$\mathrm{D}$ for Delivery and

$\mathrm{S}_{\mathrm{y}}$ represent the sustainability.

The additive model would establish a relation between $S_{\mathrm{y}}$ and the three parameters as

$$
\mathrm{Sy}=\beta_{1} \mathrm{~S}+\beta_{2} \mathrm{~L}+\beta_{3} \mathrm{E}+\beta_{4} \mathrm{D}+\varepsilon
$$

Model I

where $\beta_{\mathrm{i}}$ represent the coefficients for $\mathrm{i}=1 \ldots 4$ and $\varepsilon$, the error factor. The validity of the additive model is questionable as it implies that an extremely low to negligent value of one of the key parameters could be compensated by a large value of the other parameter thereby giving a high value of sustainability

A multiplicative model is therefore preferable and can be given as:

$$
\mathrm{S}_{\mathrm{y}}=\mathrm{k} \times \mathrm{S} \times \mathrm{L} \times \mathrm{E} \times \mathrm{D}
$$

Model II

Here, a low score of any one of the parameters is sure to lower the sustainability of the class in question.

$\mathrm{S}$ (Skills) As a student attempts to take a course having neither the necessary background nor the prerequisites for the course is likely to be "not skilled" to take the course, the corresponding S factor will be close to zero. It has been observed that students scoring high on Scholastic Aptitude 
Test (SAT) tend to be better skilled. This could be due to better study habits and correct attitudes developed while preparing for the examination. Skills can therefore be directly correlated to SAT scores and for the purpose of this study, the percentile of SAT scores can be taken as a measure of skills. A class with an average SAT percentile of 90 can be considered better prepared for the course than a class whose average percentile is 60 . The maximum value of $\mathrm{S}$ will therefore be 1 .

L (Level) This measures the level at which a course is taught. The levels at which a course can be taught can be split into 5 categories and can take the following values. It is to be noted that higher the level at which a course is taught, a course is likely to be received by a more mature group of students.

$\begin{array}{ll}\text { Value of } & \text { Nature of the course } \\ .2 & \text { beginner's course at the undergraduate level } \\ .4 & 200 \text { level at the undergraduate level } \\ .6 & 300 \text { level at the undergraduate level } \\ .8 & \text { senior at the undergraduate level } \\ 1.0 & \text { course at the graduate level }\end{array}$

E (Effort) Effort can be measured by the proportion of time a student can devote to curricular activities not counting the class duration. One of the ways this could be assessed is by the current, average Grade Point Average (GPA) of the class. The presumption is justifiable for the simple reason that greater the effort exerted by the student, greater the GPA.

D (Delivery) Delivery represents the way knowledge is imparted from the instructor to the student. All educational methods indicated in Table 1. are capable of rendering the transfer of knowledge. In order to assess the extent to which each method is successful, we propose to start ranking the methods starting from 1 to 6 , depending on the number of skills a delivery method addresses. For example, delivery by means of lecture only (addressing "remember", and "understand" the first two steps of Bloom's taxonomy), is ranked 2 out of 6.

$\mathrm{k} \quad$ constant of multiplication.

It is to be noted that Model II presented measures educational sustainability as a product of the four factors: Skills (S), Course Level (L), Effort (E), and Delivery (D). Low scores on one or more of the factors will cause the sustainability to decrease. Since all the four factors must exist or take a value greater than zero for the sustainability to be measured, it can be said that

$$
\mathrm{S}_{\mathrm{y}}=0 \text { when } \mathrm{S}, \mathrm{L}, \mathrm{E} \text {, or } \mathrm{D}=0 \text {, }
$$

Since the maximum value taken by each of the four factors is 1 , the highest level of sustainability is 1 , the constant of multiplication " $\mathrm{k}$ " must therefore be equal to 1.

Taken individually, $\mathrm{S}_{\mathrm{y}}$ is a linear function of each one of the four factors while keeping the other three constant. With the combination of other factors, Sy is likely to exhibit non-linearity.

\section{Results and Interpretation}

A Monte Carlo simulation was carried out for 300 repetitions using the multiplicative model of sustainability using the following parameters:

Skills(S): This was allowed to vary from $25^{\text {th }}$ percentile to $100^{\text {th }}$ percentile.

Level (L): This was allowed to vary from 1 to 5 , where 1 represented the course being offered during the freshman year of college progressing to 5 representing the graduate level.

Effort (E): $\quad$ Measures the average G.P.A. of the students enrolled to take the course. This is allowed to vary from 2 to 4 on a scale of 4 .

Delivery (D): Represents the number of characteristics of Bloom's taxonomy that the delivery method addresses. Range of this characteristic varies from 1 to 6.

It is to be noted that individual educational institutions can set the range of parameters to those in use at the institution and obtain revised sustainability averages. One can conclude from the multiplicative model used that sustainability of a course will be higher when each of the four parameters approaches the value 1 .

Simulation was carried out using data collected on SAT scores and percentiles (10) from 84 schools Pennsylvania (11). The data was further subdivided into four categories of schools comprising of:

-Pennsylvania State System of Higher Education

-Pennsylvania State supported schools 
-Other schools in Pennsylvania with the exclusion of the first two categories

-All 84 schools combined

The results of the descriptive analysis of sustainability are presented in Table 2. The results of the simulation are presented below:

Table 2. Descriptive Statistics - Sustainability

\begin{tabular}{lllll}
\hline Statistical & $\begin{array}{l}\text { PASSHE } \\
\text { Measures }\end{array}$ & $\begin{array}{l}\text { Pennsylvania } \\
\text { State Supported } \\
\text { Schools }\end{array}$ & $\begin{array}{l}\text { Other } \\
\text { Schools }\end{array}$ & $\begin{array}{l}\text { All Schools } \\
\text { (Pennsylvania) }\end{array}$ \\
\hline Mean & & & & \\
Standard Error & 0.143360361 & 0.157777621 & 0.193097754 & 0.183126277 \\
Median & 0.007224617 & 0.047971609 & 0.00644955 & 0.005950116 \\
Mode & 0.146406261 & 0.154934781 & 0.193313121 & 0.180520341 \\
Standard Deviation & 0.150670521 & \#N/A & 0.170570401 & 0.170570401 \\
Sample Variance & 0.027032043 & 0.095943218 & 0.052396392 & 0.054533713 \\
Kurtosis & 0.000730731 & 0.009205101 & 0.002745382 & 0.002973926 \\
Skewness & -1.083684027 & -5.541393379 & -0.664926186 & -0.808461297 \\
Range & -0.314435833 & 0.042247444 & -0.261468152 & -0.088206945 \\
Minimum & 0.08244236 & 0.184784601 & 0.201841641 & 0.210370161 \\
Maximum & 0.09381372 & 0.06822816 & 0.07675668 & 0.06822816 \\
Sum & 0.176256081 & 0.253012761 & 0.278598321 & 0.278598321 \\
Count & 2.007045047 & 0.631110482 & 12.74445176 & 15.38260729 \\
Confidence Level (95.0\%) & 14 & 4 & 66 & 84 \\
& 0.015607837 & 0.15266707 & 0.012880641 & 0.011834541 \\
\hline
\end{tabular}

5.1 The average sustainability of schools in Pennsylvania varies from a minimum value of $14.37 \%$ to a maximum of $19.31 \%$.

5.2 Inclusion of all schools in the sample has the effect of bringing down the maximum sustainability by around $3.7 \%$.

5.3 The average sustainability of all PASSHE schools is $14.34 \%$ and is fairly constant across the member schools as indicated by the sample having the lowest standard deviation among all the four groups.

5.4 It can be seen from Table 2. that skewness for Pennsylvania state supported schools is positive. This supports the fact that the sustainability scores of some schools in the sample are way above the average ones. Though sample considered is comprised of state supported schools, there is a wide difference in their sustainability.

5.5 The skewness for the other three types of samples is negative illustrating the fact that the sample is made up schools accepting students with lower than average SAT scores.

5.6 The part played by keeping the factor $\mathrm{L}$ at various fixed values while the other parameters behaved in a random fashion are presented in Table 3 .

Table 3. Influence of Course Level (L) on Sustainability

\begin{tabular}{lllllll}
\hline & Freshman & Sophomore & Junior & Senior & Graduate & \\
\hline Course Levels & $\mathbf{0 . 2}$ & $\mathbf{0 . 4}$ & $\mathbf{0 . 6}$ & $\mathbf{0 . 8}$ & $\mathbf{1 . 0}$ & Random \\
Mean & 0.036539 & 0.119332 & 0.192134 & 0.251181 & 0.326689 & 0.18006 \\
Std. Dev & 0.009754 & 0.068525 & 0.102250 & 0.145913 & 0.176338 & 0.146225 \\
Best Case & 0.152497 & 0.330003 & 0.557855 & 0.73198 & 0.996231 & 0.82497 \\
Worst Case & 0.021006 & 0.022105 & 0.032939 & 0.034081 & 0.051154 & 0.01131 \\
95\% C Level & 0.001108 & 0.007786 & 0.011618 & 0.016578 & 0.020035 & 0.016617
\end{tabular}

Whereas the first five columns of the table represents the five fixed levels of the parameter (L), the last column represents the results obtained for a randomly generated value of L. 
It is to be observed that the level at which a course is taught will increase sustainability. But, it is to be noted that schools are locked in to offering a course at a certain fixed level because of the need to cover all the required courses prior to a student graduating in a given period of time (usually 4 years).

Also to be noted is the fact that whereas the mean and best case performance improved with the level, the performance under a worst case scenario remained very low. This could mean that lack of required skills and necessary effort by and of the students keeps the course at a low sustainability level irrespective of the level at which it is taught.

Linearity of all the descriptive statistical measures as indicated in the corresponding row headers is observed as is indicated in the Figure 5. The results indicate that offering a course at the highest possible level is one of the ways to greater sustainability. However, it is observed that the combined effect of parameters on sustainability is definitely not linear as supported by the histograms in Figure 4.
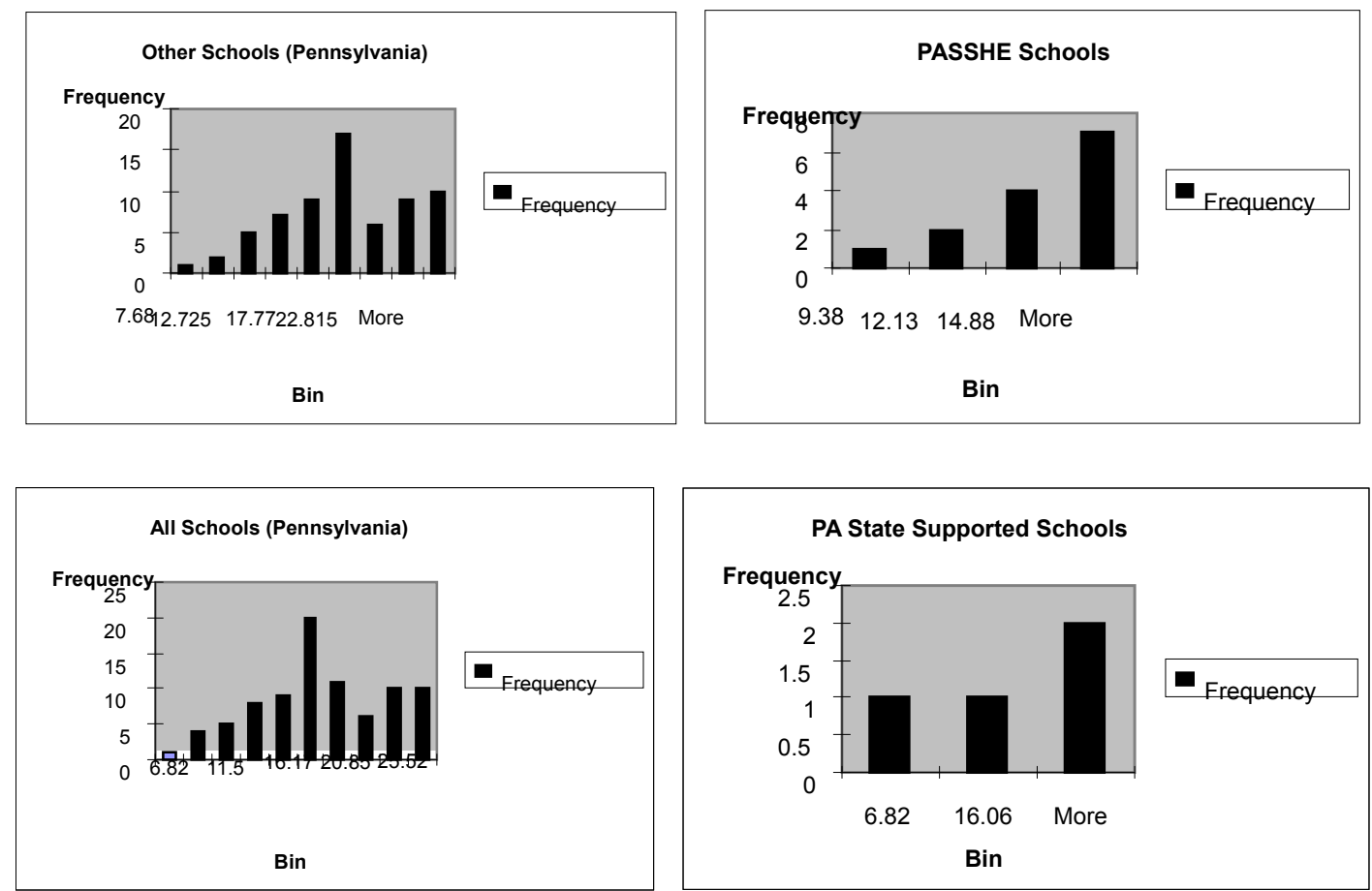

Figure 4. Histograms of Distribution of Sustainability

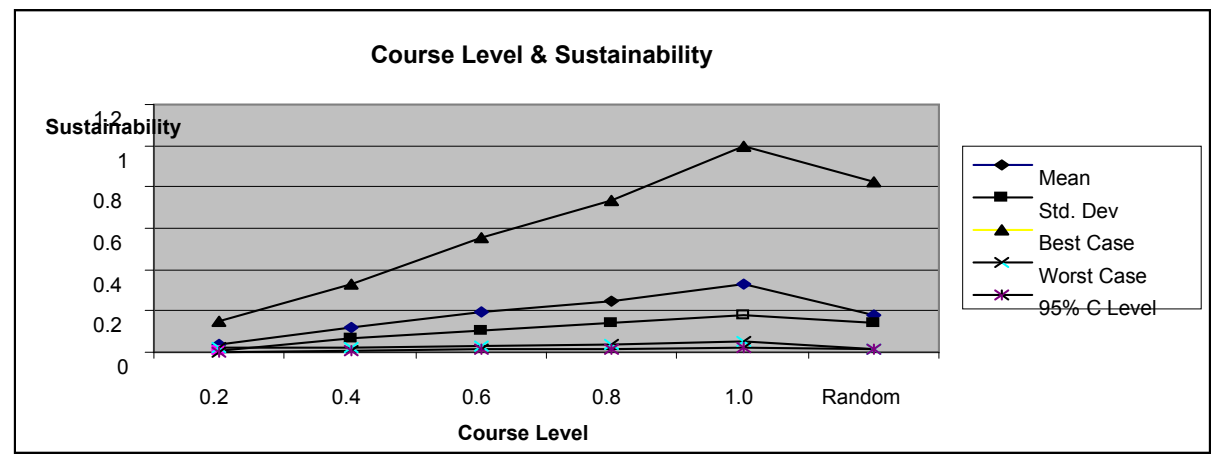

Figure 5. Course Level and Sustainability

5.7 Effort is the parameter measured by the average GPA of the class is entirely student dependent and is a perfect example of a random variable

5.8 The second controllable factor is the mode of Delivery (D). Table 1. lists the various modes of delivery of a lecture along with their ranks based on the number of characteristics of Bloom's taxonomy addressed by the particular mode. It is to be noted that not all modes can be applied to all situations in higher education. The delivery 
mode, especially at levels where students are first introduced to the concepts requires extensive remembering, memory and vocabulary recognition skills. Efforts to change the mode of delivery in an introductory course in accounting have been made by Diller-Hass (2004) and by Gupta et al. (2006). A Similar attempt in the setting of a language classroom is made by Richard-Amato (1988). Further investigation is needed to determine the optimal mode of lecture delivery.

\section{References}

[Online] Available: http://media.Collegeboard.com/digitalSevices/SAT-Percentile-Ranks-Composite-CR2012.pdf

Anderson, L. \& Krathwohl, D. A. (2001). Taxonomy for Learning, Teaching and Assessing: A Revision of Bloom's Taxonomy of Educational Objectives, Longman, New York.

Bloom, B.S., Engelhart, M. D., Furst, E. J., Hill, W. H., \& Krathwohl, D. R. (1956). Taxonomy of educational objectives: the classification of educational goals; Handbook I: Cognitive Domain New York, Longmans, Green.

Diller-Hass, A. (2004). "Time to change introductory accounting”. The CPA Journal, 74(4), 60-62.

Gerlach, J. M. (1994). "Is this collaboration?" Collaborative Learning: Underlying Processes and Effective Techniques, New Directions for Teaching and Learning. No. 59. (CL)

Gupta, Sanjay, Elson Raymond J., and Ostapski, Andrew. (2006). A Novel Approach to Teach Accounting, [Online] Available: Community.cengage.com

Retrieved from data collected from school websites

Richard-Amato, P. A. (1988). Making it happen: Interaction in the Second Language classroom: From Theory to Practice. New York: Longman.

Saunders, G. and Christopher, J.E. (2003). "Teaching outside the box: A look at the use of some nontraditional teaching models in accounting principles courses", The Journal of American Academy of Business, 3(1/2), $162-165$.

Smith, B. L., and Macgregor, J. T. (1992). "What is collaborative learning?" A Sourcebook for Higher Education. National Center on Postsecondary Teaching, Learning, \& Assessment, Syracuse University. (CL).

United Nations.9. (1987). "Report of the World Commission on Environment and Development." General Assembly Resolution 42/187, 11 December 1987. Retrieved: 2007-04-12. 